\title{
Comparative measurements between the results achieved with reference method and the optical method for determination of PM10 dusts in ambient air
}

\author{
Marius Kovacs ${ }^{1 *}$, Angelica-Nicoleta Călămar ${ }^{1}$, Lorand Toth $^{1}$, Sorin Simion ${ }^{1}$, and \\ Alexandru Simion $^{1}$ \\ ${ }^{1}$ National Institute for Researchand Development in Mine Safety and Protection to Explosion - \\ INSEMEX Petroşani,
}

\begin{abstract}
The current paper aims to determine the actuality of the optical method of measuring $\mathrm{PM}_{10}$ dusts powders compared to the reference method (gravimetric method). According to the Integrated National Plan in the field of Energy and Climate Change 2021-2030, Romania must implement a program to reduce impact on atmosphere, including air quality monitoring, thus leading to an increase in the number of monitoring points and an increase in the number of samples required for monitoring.

Currently, $\mathrm{PM}_{10}$ dust monitoring stations use the gravimetric method, consisting in absorbing a known volume of air on filters and weighing the dust deposited on them. As the use of this method requires a minimum of 3 days, it is necessary to apply an alternative measuring method, with short response time, namely the optical method.

Parallel experimentation of the two measuring devices that use different principles was performed in several series of measurements at an economic agent that has the obligation to monitor dust at premises borders.

Results obtained from comparison of the two devices can support future researchers in order to find limitations of the optical method of measuring $\mathrm{PM}_{10}$ dusts and to validate the method, in order to use it routinely.
\end{abstract}

\section{Preamble}

The ISO 7708/2000 standard defines the sampling conditions for suspended dust from the environment and from workplaces, in order to assess as accurately as possible their impact on human health and the environment. Also, depending on the aggressiveness, respectively size of particles, the fractions of inhalable (SPM), thoracic (PM10) and breathable (PM4) dusts were defined, indicating at the same time the retention efficiency of the new devices, depending on the aerodynamic diameter of particles [1].

In general, the efficiency of samplers / devices is influenced by several factors such as: speed, humidity, temperature, barometric air pressure, etc.

\footnotetext{
*Corresponding author: marius.kovacs@insemex.ro
} 
The wide range of different dusts and particle sizes in the ambient air, has led to diversification of sampling and quantification equipment for the aforementioned fractions.

\section{Requirements for methods and apparatus for the determination of dust concentrations in suspension}

Methods for determining dust particles in suspension may be with or without prior dust sedimentation.

Among determination methods with previous dust sedimentation, we mention: gravimetric, optical, electrical methods, radioactive isotopes method, etc.

Among determination methods without prior dust sedimentation, we mention: optical, electrical, acoustic method, etc.

The gravimetric method of determining suspension dust is a simple and safe method, giving the possibility to directly determine the mass of airborne particles. It also allows accurate representation of the danger to human health in relation to the mass of dust inhaled, regardless of the composition and dispersion of suspended particles.

Optical methods for determining dust concentrations in air, namely by light absorption (photometric or luminescence), electrical, laser probing, radioactive isotopes, etc., are widely used due to the great possibilities of automating the measurement and transmission of information processes, but are adversely affected by the physical and chemical composition of dusts.

Currently, the gravimetric method for determining dust concentrations in the environment and work environment is widespread in all European countries, which is why the maximum permissible limits in these countries, including our country, are expressed gravimetrically in micrograms or milligrams per $\mathrm{m}^{3}$.

Standard SR EN 12341/2014 "Air quality. A standardized method of gravimetric measurement for the determination of PM10 or PM2.5 fraction of particulate matter in the environment", specifies requirements and performance for samplers of dust hazardous to human health, PM10 and PM2.5, in accordance with Council Directive 96/62/EC and the Daughter Directive.

The standard also specifies the conditions of equivalence to laboratory and field testing of a PM10 dust sampler (non-certified) compared to a reference sampler (certified).

At the same time, the reference measurement method must be gravimetric and the apparatus must consist of a separator (first stage - impactor), for retaining particles larger than $10 \mu \mathrm{m}$ from air, and a filter, (second stage), on which particles below $10 \mu \mathrm{m}$, representing the PM 10 fraction, are retained.

The amount of air circulated through the device is ensured by a vacuum pump and recorded by a metrologically verified meter.

\section{Description of devices used for performing comparative measurements}

\subsection{Reference device for gravimetric determination of $\mathrm{PM}_{10}$ particles in the environment}

According to the SR EN 12341/2014 standard, LVS-PM10 (low volume sampler) or HVSPM10 (high volume sampler) or WRAC-PM10 (very high volume) can be used as certified reference devices for sampling environmental dust [2].

The device made at INCD INSEMEX was used for performing the measurements. It complies with all the constructive and functional dimensions of the LVS-PM10 certified 
device from the SR EN 12341/2014 standard, both in terms of the two air dust separation stages (impactor and filter) and of the systems for suction and metering the air flow aspirated through the filter.

The main components of the PM10 sampler of dust from the environment are shown in Figure 1. The operating principle is as follows: with the help of the vacuum pump (6), dusted air is sucked through the separator (1) which retains particles having dimensions larger than $10 \mu \mathrm{m}$. Breathable particles below $10 \mu \mathrm{m}$ are then retained on the fiberglass filter, fitted in the holder (3). The volume of air sucked through the filter is determined by the meter (4). The connection between the installation's components is made by means of elastic hoses (3). Adjustment and correction of flow rate at $2.3 \mathrm{~m}^{3} / \mathrm{h}$ is achieved with the help of the valve (5) [3].

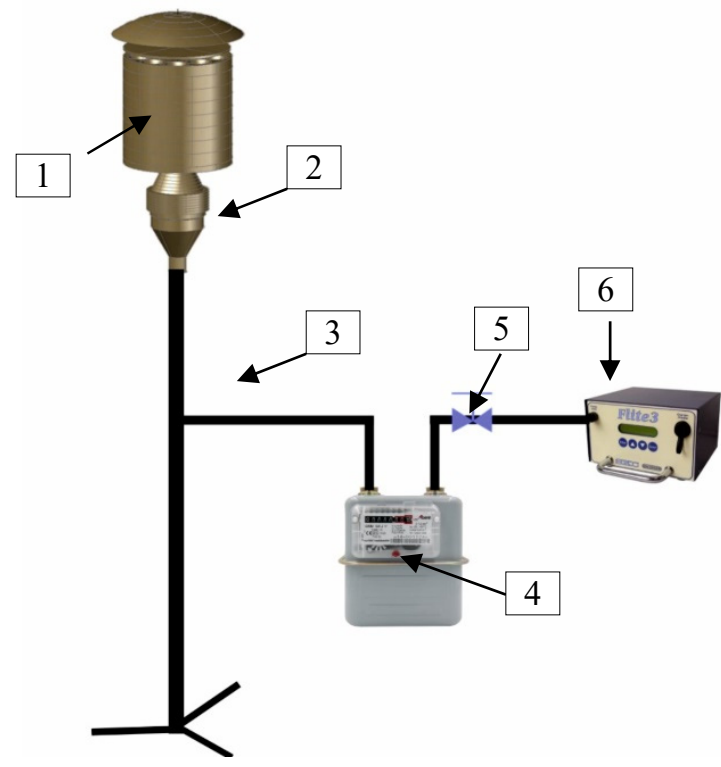

1 - separator,

2 - filter holder,

3 - connecting hose,

4 - air meter,

5 - flow control valve,

6 - vacuum pump with battery.

Fig.1. PM10 dust sampler. Component parts.

The overview and the direction of dusted air flow in the separator, are shown in Figure 2.

The separator consists of 8 tubes with the help of which the impact of particles with the lower wall occurs, at a certain calculated speed, thus achieving the retention of particles larger than $10 \mu \mathrm{m}$. By changing the direction of effluent flow, particles below $10 \mu \mathrm{m}$ pass through the separator and are retained on the filter [4].

According to the standard mentioned above, air flow through the device is $2.3 \mathrm{~m}^{3} / \mathrm{h}$ for 8 hours.

Calculating the impact velocity (v) of particles at the exit from the impact tubes we have:

$$
v=\frac{Q}{S}=\frac{Q}{8 \cdot \frac{\pi \cdot d^{2}}{4}}=\frac{2,3}{3600 \cdot 8 \cdot \frac{3,14 \cdot 0,0065^{2}}{4}}=2,4 \mathrm{~m} / \mathrm{s}
$$

where: Q - air flow in the separator $\left(2.3 \mathrm{~m}^{3} / \mathrm{h}\right)$;

$\mathrm{S}$ - total active section of impact tubes $\left[\mathrm{m}^{2}\right]$;

$\mathrm{d}$ - inside diameter of impact tubes $[6,5 \mathrm{~mm}]$. 

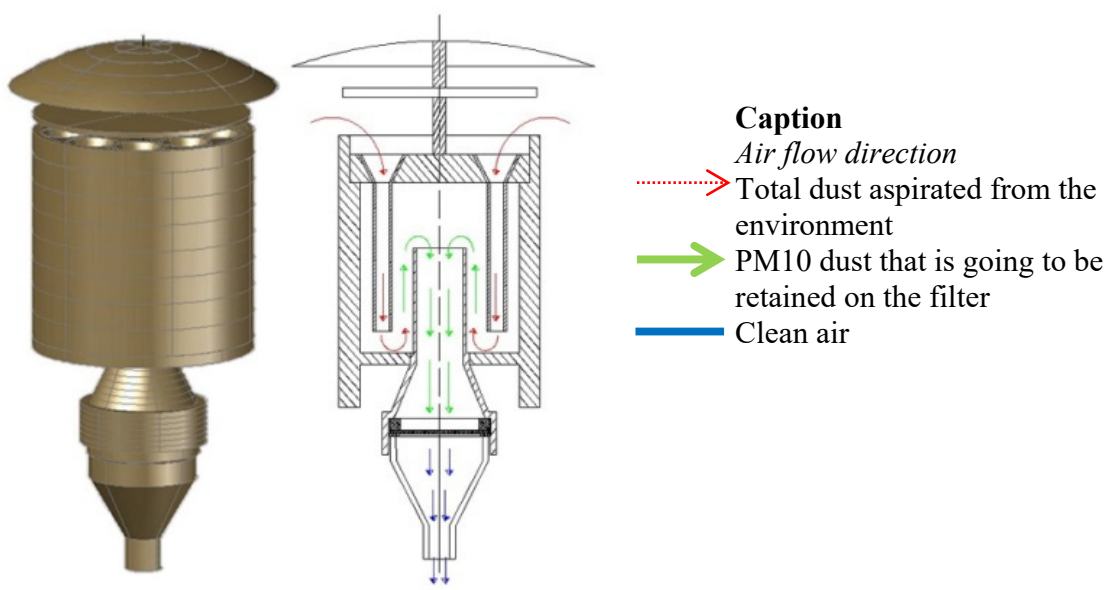

Fig. 2. Overview and direction of dusted air flow in the separator (impactor).

Fiberglass filters that are weighed before and after sampling are used for determination of PM10 dust gravimetric concentrations.

The air meter is metrologically checked and has a calibration certificate.

"FLITE 2" type vacuum pump is supplied with a voltage of $220 \mathrm{~V}$ A.C.

The gravimetric concentration $(\mathrm{C})$ of PM10 dust is determined by the relation:

$$
\mathrm{C}=\frac{\mathrm{G}_{2}-\mathrm{G}_{1}}{\mathrm{~V}} \mathrm{mg} / \mathrm{m}^{3}
$$

$\mathrm{G}_{2}, \mathrm{G}_{1}$ - final and initial masses of the filter [mg];

$\mathrm{V}$ - volume of sucked air $\left[\mathrm{m}^{3}\right]$.

\subsection{Optical device for determination of PM10 particles integrated in the FIDAS 200 auto laboratory}

The optical method principle of the device consists in aspiration of an air volume and optical measurement of particle sizes, on particle size classes.

Sampling and analysis of assays is performed by using the FIDAS 200 device, integrated in the institute's auto-laboratory, made in accordance with SR EN 16450: 2017.

The air is sucked in with the help of the AirmoPure-D pump, supplied by the autolaboratory [5].

FIDAS 200 device's main panel of the control unit is presented in Figure 3.

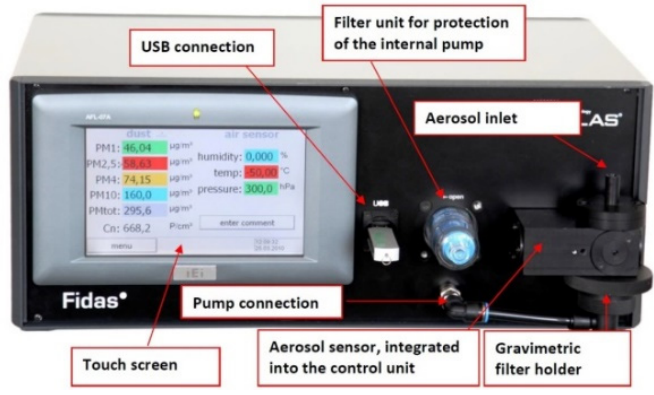

Fig. 3. FIDAS 200 - Main panel of measurement and control unit. 
The device consists of an optical spectrometer, determining the size of particles through light dispersion [3].

The particles move in an optically differentiated measuring volume, homogeneously illuminated with polychromatic light (Figure 4). Each particle generates a pulse of dispersed light, detected at an angle of $85^{\circ}-95^{\circ} \mathrm{C}$. Concentration of dust particles results from the number of dispersed pulses. Amplitude of the dispersed light pulse is a measure of the particle size diameter.
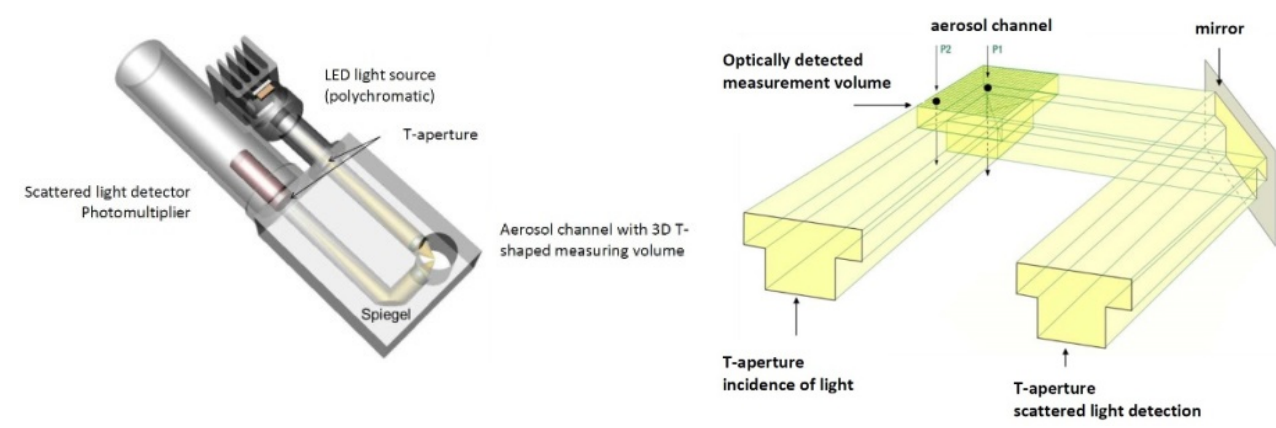

Fig. 4. The FIDAS device's principle of operation.

Using the polychromatic light source (LED) in combination with a $90^{\circ}$ dispersed light detection, an accurate, unambiguous gravimetric calibration curve in the Lorenz-Mie range can be, for a given analysed dust.

In addition to signal amplitude for each individual particle, the sensor also measures its length. This signal length is directly proportional to speed of particles in the sensor.

For actual determination of dust concentration, flow rate and particle speed in the sensor must be continuously constant.

Measurements are automatically recorded in the internal memory of the FIDAS 200 (optical) device, and data can be viewed and downloaded to the auto-laboratory laptop, via the IOVIS software.

Also, the software offers the possibility to centralize all parameters determined by the auto-laboratory's complementary equipment.

Weather data and flows circulated in the device are automatically recorded and downloaded to the mentioned laptop.

\section{Carrying out in situ comparative measurements, between the LVS-PM10 reference gravimetric device and the FIDAS 200 optical device}

During $17 \div 21.02 .2021$, comparative measurements were performed with the two devices, namely the reference gravimetric device LVS-PM10 and the optical device FIDAS, within the industrial premises of an economic unit, where heat treatment technology of metallic, non-metallic and other materials parts is applied, from whose production hall's chimneys gases and powders were evacuated.

Overview of optical device's equipment, endowment of the auto-laboratory and of the location where the comparative measurements were performed, are shown in Figure 5. 


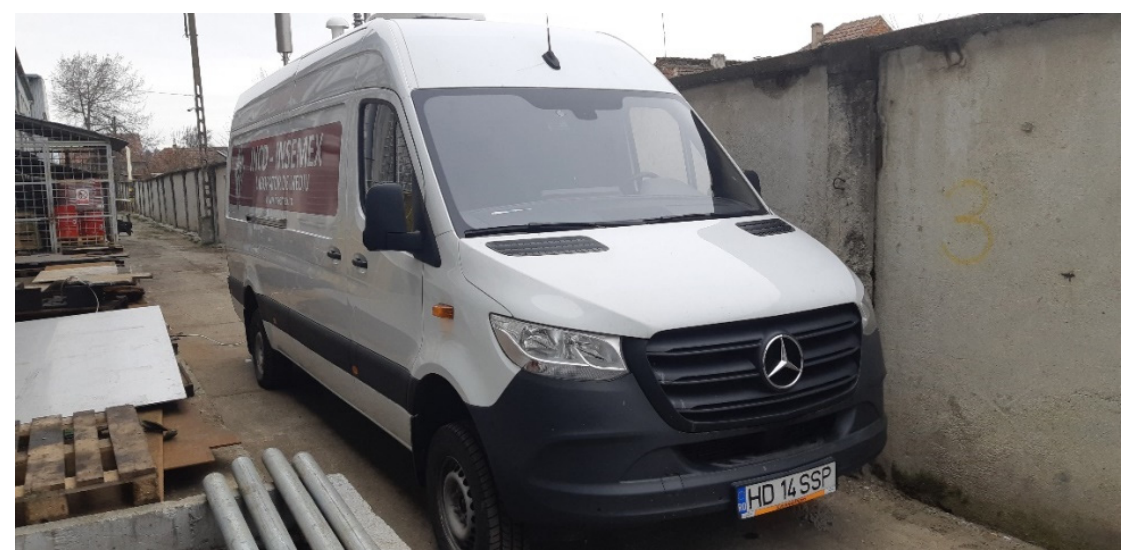

Fig. 5. Overview of the location where the parallel measurements were performed

\subsection{Overview of comparative determinations performed}

The stations / locations of devices, dust sampling periods and hourly and average concentrations determined with the two equipments, are shown in Table 1.

Table 1. Dust sampling concentrations determined with the two equipments.

\begin{tabular}{|c|c|c|c|c|c|}
\hline $\begin{array}{c}\text { Place of } \\
\text { sampling / } \\
\text { Place of } \\
\text { measurement }\end{array}$ & $\begin{array}{l}\text { Period of } \\
\text { sampling }\end{array}$ & $\begin{array}{c}\text { Determined } \\
\text { quality } \\
\text { indicators / } \\
\text { determined } \\
\text { parameters }\end{array}$ & $\begin{array}{c}\text { Hourly dust } \\
\text { concentrations } \\
\text { determined } \\
\text { with FIDAS } \\
200 \text { equipment } \\
{\left[\mu \mathrm{g} / \mathrm{m}^{3}\right]}\end{array}$ & $\begin{array}{c}\text { Average dust } \\
\text { concentrations } \\
\text { determined at } \\
24 \text { hours with } \\
\text { FIDAS 200 } \\
\text { equipment } \\
{\left[\mu \mathrm{g} / \mathrm{m}^{3}\right]}\end{array}$ & $\begin{array}{c}\text { Average dust } \\
\text { concentrations } \\
\text { determined at } \\
24 \text { hours with } \\
\text { LVS } \\
\text { equipment } \\
{\left[\mu \mathrm{g} / \mathrm{m}^{3}\right]}\end{array}$ \\
\hline 1 & 2 & 3 & 4 & 5 & 6 \\
\hline $\begin{array}{l}\text { The premises } \\
\text { of the } \\
\text { economic } \\
\text { agent, the } \\
\text { northern part } \\
\text { of the } \\
\text { administrative } \\
\text { building }\end{array}$ & $17 \div 18.02 .2021$ & $\mathrm{PM}_{10}$ dust & $\begin{array}{c}35.67 \\
41.79 \\
44.4 \\
49.05 \\
61.2 \\
62.71 \\
48.56 \\
41 \\
35.24 \\
31.82 \\
38.23 \\
41.84 \\
39.3 \\
37.69 \\
29.77 \\
29.98 \\
38.4 \\
37.25 \\
47.46 \\
52.45 \\
56.15 \\
52.74 \\
55.84 \\
54.66 \\
41.82\end{array}$ & 44.20 & 42.57 \\
\hline
\end{tabular}




\begin{tabular}{|c|c|c|c|c|c|}
\hline 1 & 2 & 3 & 4 & 5 & 6 \\
\hline $\begin{array}{l}\text { The premises of } \\
\text { the economic } \\
\text { agent, the } \\
\text { eastern part of } \\
\text { the } \\
\text { administrative } \\
\text { building }\end{array}$ & $18 \div 19.02 .2021$ & $\mathrm{PM}_{10}$ dust & $\begin{array}{c}37.21 \\
43.33 \\
46.94 \\
47.24 \\
59.39 \\
60.9 \\
46.75 \\
32.19 \\
33.43 \\
37.63 \\
36.42 \\
40.03 \\
37.49 \\
35.88 \\
33.58 \\
33.79 \\
36.59 \\
41.06 \\
45.65 \\
48.64 \\
50.34 \\
48.93 \\
51.62 \\
50.85 \\
40.49 \\
\end{array}$ & 43.05 & 46.62 \\
\hline $\begin{array}{l}\text { The premises of } \\
\text { the economic } \\
\text { agent, the } \\
\text { western part of } \\
\text { the } \\
\text { administrative } \\
\text { building }\end{array}$ & $19 \div 20.02 .2021$ & $\mathrm{PM}_{10}$ dust & $\begin{array}{c}29.32 \\
35.44 \\
38.05 \\
58.3 \\
54.85 \\
47.8 \\
42.21 \\
34.65 \\
28.89 \\
25.47 \\
31.88 \\
35.49 \\
32.95 \\
31.34 \\
30.48 \\
28.4 \\
32.05 \\
30.9 \\
41.11 \\
46.1 \\
49.8 \\
46.39 \\
49.49 \\
48.31 \\
37.95 \\
\end{array}$ & 38.70 & 33.1 \\
\hline
\end{tabular}




\begin{tabular}{|c|c|c|c|c|c|}
\hline 1 & 2 & 3 & 4 & 5 & 6 \\
\hline $\begin{array}{l}\text { The premises of } \\
\text { the economic } \\
\text { agent, the } \\
\text { southern part of } \\
\text { the } \\
\text { administrative } \\
\text { building }\end{array}$ & $20 \div 21.02 .2021$ & $\mathrm{PM}_{10}$ dust & $\begin{array}{c}25.45 \\
31.57 \\
34.18 \\
38.83 \\
48.98 \\
49.49 \\
38.34 \\
30.78 \\
25.02 \\
21.6 \\
28.01 \\
31.62 \\
29.08 \\
27.47 \\
22.68 \\
19.76 \\
28.18 \\
27.03 \\
37.24 \\
42.23 \\
52.42 \\
42.52 \\
32.8 \\
38.57 \\
41.1\end{array}$ & 33.79 & 28.45 \\
\hline
\end{tabular}

\subsection{Interpretation of determinations performed with the LVS PM10 device}

Analysis of values determined for a continuous period of 24 hours with the LVS gravimetric device, showed that the highest concentration of PM10 $\left(46.62 \mu \mathrm{g} / \mathrm{m}^{3}\right)$ was recorded during $18 \div 19.02 .2021$, in the eastern part of the administrative building, and the lowest $\left(28.45 \mu \mathrm{g} / \mathrm{m}^{3}\right)$ in the southern part of the building.

According to Law 104/2011 on the quality of the environment, point B2. specifies that for a mediation period of 24 hours, the maximum permissible limit value of PM10 is 50 $\mu \mathrm{g} / \mathrm{m}^{3}$, provided that this value is not exceeded more than 35 times in a calendar year. Also, the tolerance margin must be $50 \%$, an obligation that came into force on 01.01.2007.

Compared to the permissible limit of $50 \mu \mathrm{g} / \mathrm{m} 3$, we have determined that in none of the analysed periods this limit was exceeded.

\subsection{Interpretation of determinations performed with the FIDAS 200 device}

With this device, values of the hourly optical concentrations were determined in the first stage, recording the maximum and minimum, the average of the optical measurements and the average of the gravimetric measurements.

The device automatically performs the operation of converting determined optical concentrations into gravimetric concentrations, by the standard dust used for calibrating the device.

The graphs of determinations performed with the FIDAS device in the four analysed periods is shown in Figure 6.

These graphs show that the average of optical measurements differs from the average of gravimetric measurements.

The advantage of these optical determinations is that the hours in which maximum and minimum concentrations have been recorded can be identified, offering the possibility of being correlated to production intensity or other causes. 


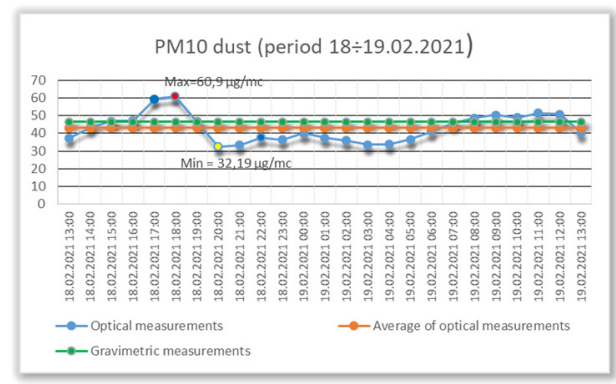

PM10 dust (period $19 \div 20.02 .2021$ )

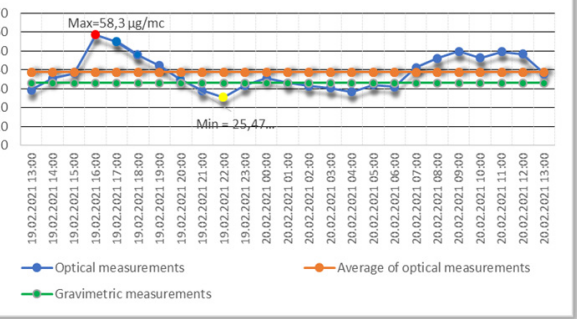

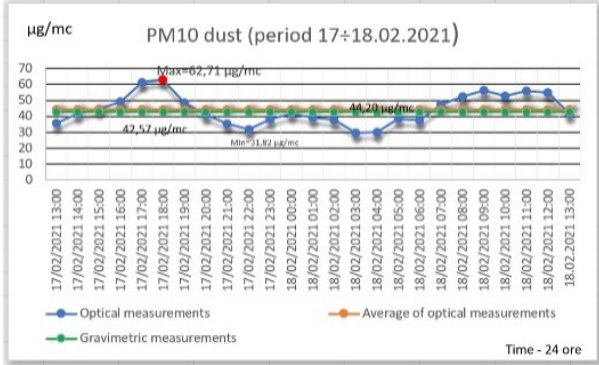

PM10 dust (perioada $20 \div 21.02 .2021$ )

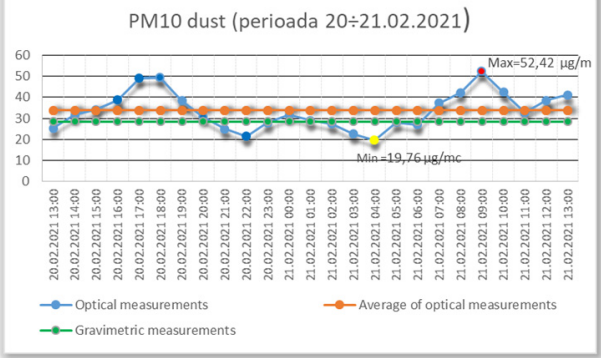

Fig.6. Continuously measured PM10 values for both optical and gravimetric measurements.

Another advantage of using the device is that it displays the comparison of concentration values determined by optical measurements with the values of concentrations converted into gravimetric units, as a result of using a standard dust to calibrate the device, incorporated in it, Figure 7.

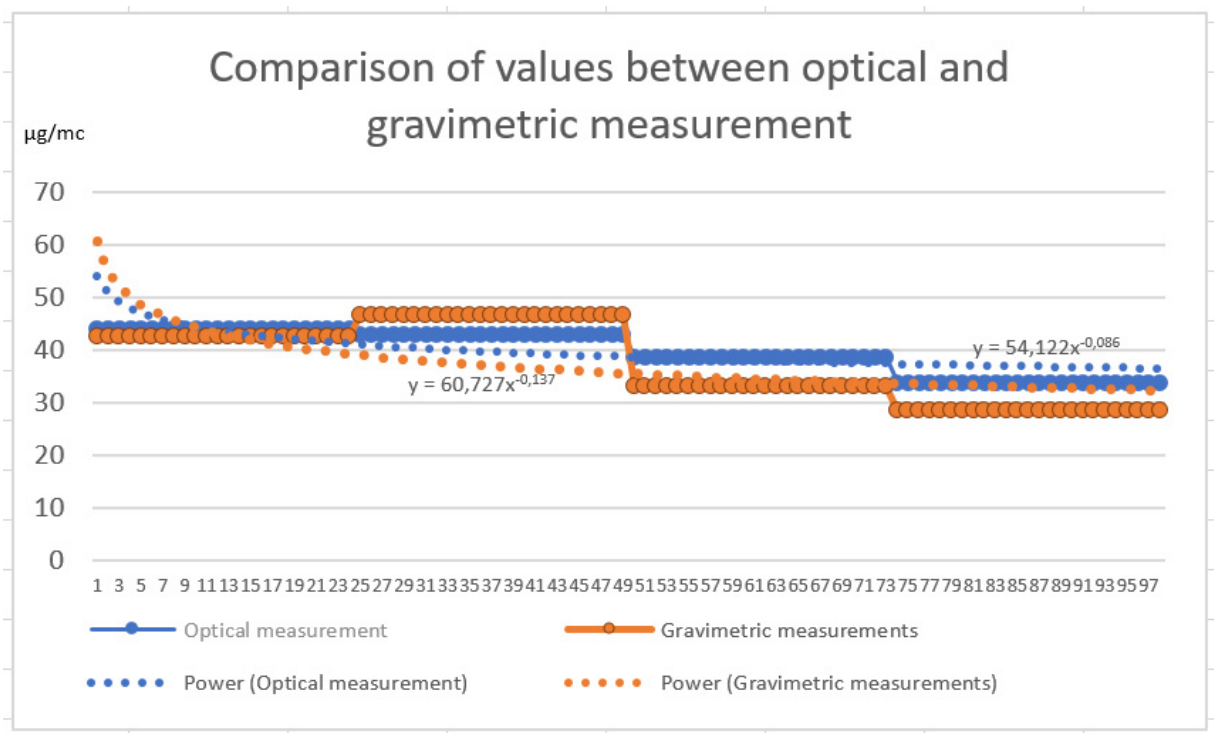

Fig.7. Comparison between converted values of optical and gravimetric measurements

The device can also plot the variation of concentrations determined in optical units and their average, in relation to different confidence intervals $\left(X_{m}+/-2\right.$ and $3 S$ and $X_{m}+/-2$ şi 3S), Figure 8a. 
Also, the graph of the variation of concentrations converted from optical units to gravimetric units and their average, in relation to different confidence intervals $\left(X_{m}+/-2\right.$ and $3 \mathrm{~S}$ și $\mathrm{X}_{\mathrm{m}}+/-2$ and $3 \mathrm{~S}$ ), is shown in Figure 8b.

where:

$\mathrm{X}_{\mathrm{m}}$ - average values;

$\mathrm{S}$ - standard deviation.

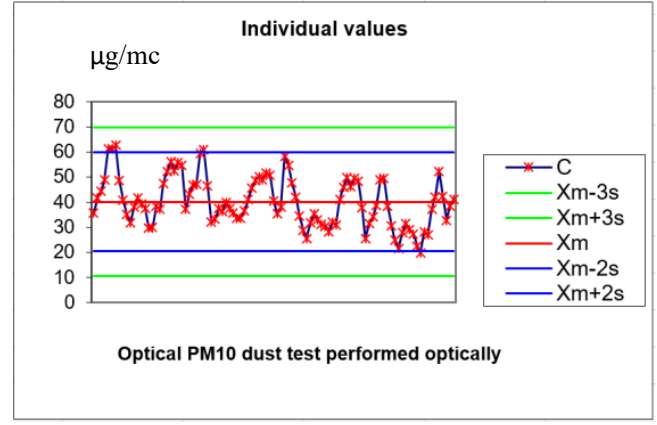

a. Graph of the variation of the concentrations determined in optical units and their average

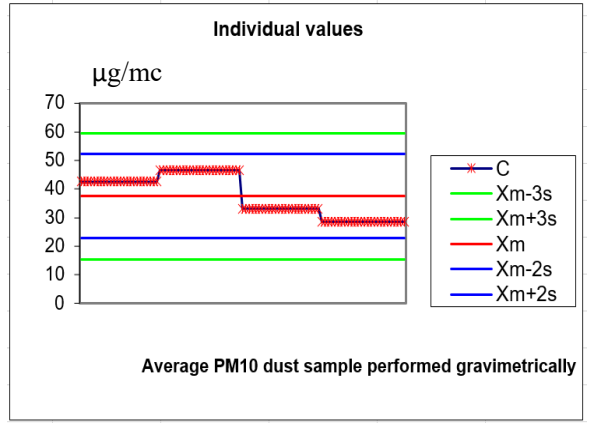

b. Graph of the variation of concentrations converted from optical units to gravimetric units and their average

Fig. 8. Graph of the variation of the concentrations determined in optical units (a) and average of gravimetric units (b).

\subsection{Comparative analysis between the two devices}

This analysis aimed at comparing the two devices, respectively gravimetric concentrations determined with the optical device and with the reference device recommended by Standard SR EN 12341/2014. Comparative measurements are shown in Table 2 [6].

Table 2. The deviation values of the FIDAS 200 device from the LVS reference device during the analysed period.

\begin{tabular}{|c|c|c|c|}
\hline $\begin{array}{c}\text { Sampling } \\
\text { period }\end{array}$ & $\begin{array}{c}\text { Mean gravimetric } \\
\text { concentrations } \\
\text { determined with the } \\
\text { LVS reference device, } \\
{\left[\boldsymbol{\mu g} / \mathbf{m}^{3}\right], \mathbf{C}_{\mathbf{1}}}\end{array}$ & $\begin{array}{c}\text { Average gravimetric } \\
\text { concentrations converted } \\
\text { from optical units to } \\
\text { gravimetric units, determined } \\
\text { with FIDAS 200, }\left[\boldsymbol{\mu g} / \mathbf{m}^{\mathbf{3}}\right], \mathbf{C}_{2}\end{array}$ & $\begin{array}{c}\text { Deviation of the FIDAS } \\
\mathbf{2 0 0} \text { device from the LVS } \\
\text { reference device, } \\
\left.\left(\mathbf{C}_{\mathbf{1}}-\mathbf{C}_{\mathbf{2}}\right) / \mathbf{C}_{\mathbf{1}} \mathbf{x} \mathbf{1 0 0}, \mathbf{[} \%\right]\end{array}$ \\
\hline $17 \div 18.02 .2021$ & 42.57 & 44.20 & -3.82 \\
\hline $18 \div 19.02 .2021$ & 46.62 & 43.05 & +7.65 \\
\hline $19 \div 20.02 .2021$ & 33.1 & 38.70 & -16.91 \\
\hline $20 \div 21.02 .2021$ & 28.45 & 33.79 & -18.76 \\
\hline
\end{tabular}

The table shows the following:

- in 3 out of 4 measurements performed, the average gravimetric concentrations recorded with the FIDAS 200 device are lower than those recorded with the LVS device,

- except for the measurements from $18 \div 19.02 .2021$, concentrations recorded with the optical device, compared to the reference, are lower by $3.82-18.76 \%$. 


\section{Conclusions and recommendations}

Currently, the gravimetric method for determining dust concentrations in the environment and work environment is widespread in all European countries, which is why the maximum permissible limits in these countries, including our country, are expressed gravimetrically.

The current paper presents operating principles of the LVS and the FIDAS 200 devices.

During $17 \div 21.02 .2021$, comparative measurements were performed with the two devices, in the industrial premises of an economic unit in which metal parts heat treatment technology is applied.

Concentrations determined with the LVS reference apparatus in the 4 analysed periods did not exceed the limit allowed by Law 104/2018, respectively $50 \mu \mathrm{g} / \mathrm{m}^{3}$.

We mention that these determinations are the real ones and can be taken into account when referring to the mentioned law.

Hourly optical measurements, recorded maximum and minimum, average optical measurements and average gravimetric measurements can be performed with the FIDAS device.

The advantage of using this device is that the hours in which maximum and minimum concentrations have been recorded can be identified, offering the possibility of being corelated to production intensity or other causes.

Gravimetric measurements determined with the two devices are different because the FIDAS 200 device was calibrated to a standard dust with certain physical and chemical properties, while the LVS device determined dust present in situ.

Consequently, the values of gravimetric concentrations recorded with the FIDAS 200 device are not the real ones but only indicative, while concentrations determined with the LVS device are the real ones.

For the current use of the FIDAS 200 optical device in situ for dusts of different nature, it is recommended to perform parallel measurements with the LVS reference device, in order to establish an equivalence, respectively corrections, between these equipment.

\section{References}

1. The Integrated National Plan in the field of Energy and Climate Change 2021-2030 - European Commission

2. $\quad$ SR EN $12341(2014)$

3. M. Kovacs, L. Kovacs, L. Toth, A. Călămar, International Symposium ECOIND, , Researches for designing an apparatus for sampling airborne particles PM10 and PM2,5 (Bucureşti, 2007)

4. M. Kovacs, L. Kovacs, G. Ghetie, A. Calamar, L. Toth, International Symposium "Youth and Multidisciplinary Research" 13th edition ISYPMR, , Monitoring of air pollutant emissions in the vicinity of the main ventilation station of E.M. Lonea (Polytechnic University of Timisoara, 2009)

5. Operation manual - Fidas ${ }^{\circledR} 200$ the mass fraction of PM10 or PM2.5 of suspended particles

6. J Gebicki, K. Szymańska - Gdansk University of Technology, Comparative field test for measurement of PM10 dust in atmospheric air using gravimetric (reference) method and $\beta$ absorption method (Eberline FH 62-1) 